Journal of Patient-Centered

Volume 4

Issue 4 -- Health Disparities and Inequities: Part

Article 1 I

$11-6-2017$

\title{
The Path to Health Equity Through Multidisciplinary Collaboration
}

Cynthia Haq

Follow this and additional works at: https://aah.org/jpcrr

Part of the Epidemiology Commons, Health and Medical Administration Commons, Health Services Research Commons, Medical Humanities Commons, and the Primary Care Commons

\section{Recommended Citation}

Haq C. The path to health equity through multidisciplinary collaboration. J Patient Cent Res Rev. 2017;4:208-10. doi: 10.17294/2330-0698.1615

Published quarterly by Midwest-based health system Advocate Aurora Health and indexed in PubMed Central, the Journal of Patient-Centered Research and Reviews (JPCRR) is an open access, peer-reviewed medical journal focused on disseminating scholarly works devoted to improving patient-centered care practices, health outcomes, and the patient experience. 


\title{
The Path to Health Equity Through Multidisciplinary Collaboration
}

\author{
Cynthia Haq, MD \\ Department of Family Medicine and Community Health, University of Wisconsin School of Medicine \\ and Public Health, Madison, WI
}

$\mathrm{W}$ hy did this call for articles focused on health disparities result in a record number of theme submissions to the Journal of Patient-Centered Research and Reviews (JPCRR)?

Why are health systems, academic health centers, community organizations and health professional organizations launching multipronged efforts to promote health equity?

Why do health disparities matter, and what can be done to address them?

Over the last decade, health professionals and their organizations have paid greater attention to health disparities in response to a tsunami of evidence revealing that the U.S. health care system is spending more money on health care costs per capita than any other nation but achieving worse health outcomes. ${ }^{1}$ It is difficult to ignore that U.S. population health outcomes compare poorly with those measured in other highincome countries around the world. ${ }^{1}$

At the most fundamental level, the life expectancy for people living in the most affluent neighborhoods may be decades longer than for people living in low-income communities. ${ }^{2}$ People who are disadvantaged and/or living in poverty unduly suffer from increased burdens of illness in relation to those who are economically, educationally or socially well off. From pregnancy to end-of-life, researchers have amassed myriad evidence

Correspondence: Cynthia Haq, MD,

University of Wisconsin School of Medicine and Public Health, 1100 Delaphine Ct., Madison, WI, 53715, T: +1-608-263-4550,

Email: cindy.haq@wisc.edu related to differences in the quality of health care received and health outcomes experienced between the rich and poor, and among people who are white and of color. 3,4

Why the discrepancies? First, let's review a pair of definitions:

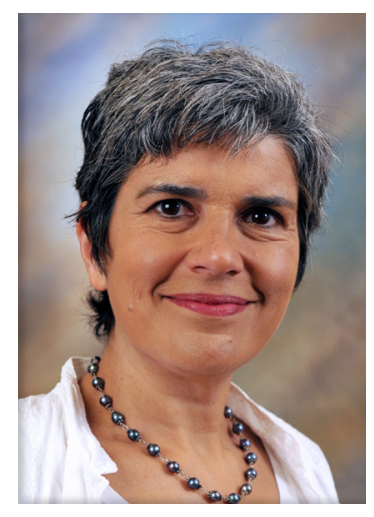

Health disparities, or absolute differences in healthrelated quality of life, morbidity and mortality rates between groups of people, reflect stark contrasts both within and between countries. ${ }^{5}$

Health inequities, or differences in health that are avoidable, unfair and unjust, result in millions of people who suffer unnecessarily and die prematurely. ${ }^{5}$

Most health disparities are, in fact, the result of a complex web of social and economic inequities. Access to affordable, high-quality health care services for all is one way to reduce health inequities and disparities. Yet health outcomes are more profoundly influenced by social, economic and environmental conditions, which in turn influence health behaviors, than by actual health care services provided. ${ }^{3,4}$

\section{Looking Beyond the Health System}

Health professionals do not have the skills, time or resources to address the "social determinants" of health and illness on their own. Promoting health equity requires collaboration among key stakeholders in health and social systems; developing strategic partnerships; and engaging across institutional boundaries to identify 
local needs, promote best practices, and establish monitoring and evaluation to ensure these efforts are mutually beneficial and sustainable over time. ${ }^{6}$

Promoting health equity requires development of new competencies such as: understanding social determinants; identifying upstream approaches to prevention; providing outreach to underserved, disadvantaged people and communities $;^{7}$ cultivating health and social policy advocacy; ${ }^{8}$ promoting multidisciplinary teamwork; integrating clinical medicine and public health; recognizing racism and its effects; ${ }^{9}$ and promoting diversity in medical education, clinical and public health services. This work also will require resources, incentives and reimbursement mechanisms to promote prevention of, in addition to treatment for, adverse health outcomes.

Pathways for health professionals to promote such changes exist, ${ }^{10}$ yet few have been well-prepared to cultivate community collaborations or advocate for change. ${ }^{11}$ Fortunately, many outstanding efforts are in progress to address these challenges.

Recognizing the complexity of this task, many groups like the American Association of Medical Colleges, ${ }^{12,13}$ Beyond Flexner, ${ }^{14}$ the Social Medicine Consortium ${ }^{15}$ and the World Health Organization ${ }^{16}$ have launched efforts that promote changes in medical education and practice to encompass these goals. The Institute of Medicine has provided a comprehensive framework to educate health professionals in how to address the social determinants of health. ${ }^{8}$ These groups have acknowledged that health equity cannot be adequately addressed through a few isolated efforts, but is best addressed in an integrated fashion throughout the curriculum and health system using a health equity framework or lens. The University of Wisconsin School of Medicine and Public Health has joined with others to develop a health equity lens and infuse content throughout its curriculum to introduce medical students to these topics. ${ }^{17}$ Targeted programs have been created to recruit and train students to address rural and urban health inequities. ${ }^{18,19}$ Early outcomes demonstrate these efforts can be successful. ${ }^{20}$

\section{Addressing Inequities in Many Forms}

The importance and timeliness of health disparities research galvanized our interest in serving as guest editors for this special issue of $J P C R R$, which includes a variety of contemporary efforts to promote health equity. In their study of measuring patient-centered outcomes, Solberg and colleagues discovered that many outcomes deemed important by patients who had experienced abdominal and/or back pain serious enough to require computed tomography or magnetic resonance imaging could not be identified through the patient's medical records. ${ }^{21}$ They also concluded that documenting patients' opinions could influence broader care practices. Despite mountains of electronic health records, researchers still need to ask patients directly about the most important outcomes that matter to them.

Hammarlund and colleagues explored knowledge, attitudes and behaviors regarding health care disparities among resident physicians in Louisiana. ${ }^{22}$ They found that residents' patient interactions changed after relatively brief educational interventions. As a result, residents wanted more information about how to access community resources to help their patients combat health disparities.

In a collaboration of several health systems, Dillon and colleagues explored the influence of patient engagement in research that has been encouraged by the federally funded Patient-Centered Outcomes Research Institute by conducting a workshop to define and measure critical outcomes of research engagement. ${ }^{23}$ This productive pilot points to the need for additional studies to engage patients in the design and conduct of research, and to carefully assess patient satisfaction with and influence on ultimate research outcomes.

A sobering study by LeCounte and Swain revealed that life expectancy at birth varies by as much as 12 years among zip codes in Milwaukee County, Wisconsin. ${ }^{24}$ Similar to the findings of Ansell and colleagues in Chicago, ${ }^{2}$ differences in life expectancy were strongly correlated with social and economic conditions. These findings point to the importance of advocacy for social and policy changes to promote health equity.

Finally, given the serious epidemic of opioid overuse and overdose deaths, Cardarelli and colleagues tested a model to improve care for patients suffering from chronic pain in rural Appalachia. ${ }^{25}$ They found promising improvements in the quality of care after a 
practice facilitator trained clinical teams in community and academic practices to implement chronic pain tools and workflows. This multisite study confirmed that clinical educational interventions can be effective in improving processes of care and interdisciplinary management of patients with chronic pain.

Recently, a bright young medical student asked during her first clinical rotation, "Why are patients treated differently depending on their insurance status or the color of their skin? Shouldn't all patients have the same chances to live healthy lives and receive the same quality of health care?"

Since health inequities are avoidable, they can be addressed! We invite you to join us and the authors of these articles to become part of the solution.

\section{References}

1. Bezruchka S. The hurrider I go the behinder I get: the deteriorating international ranking of U.S. health status. Annu Rev Public Health. 2012;33:157-73. CrossRef

2. Ansell DA. The Death Gap: How Inequality Kills. Chicago, IL: University of Chicago Press, 2017.

3. Robert Wood Johnson Foundation. County health rankings and roadmaps. http://www.countyhealthrankings.org/. Accessed August 26, 2017.

4. Hood CM, Gennuso KP, Swain GR, Catlin BB. County health rankings: relationships between determinant factors and health outcomes. Am J Prev Med. 2016; 50:129-35. CrossRef

5. San Francisco State University, Health Equity Institute. Welcome to the Health Equity Institute. Motion graphic: What is health equity? http://healthequity.sfsu.edu. Accessed January 8, 2017.

6. Ventres W, Boelen C, Haq C. Time for action: key considerations for implementing social accountability in the education of health professionals. Adv Health Sci Educ Theory Pract. 2017 Sep 12 [Epub ahead of print]. CrossRef

7. Institute of Medicine (US) Committee on Assuring the Health of the Public in the 21st Century. The Future of the Public's Health in the 21st Century. Washington, DC: National Academies Press, 2003.

8. Committee on Educating Health Professionals to Address the Social Determinants of Health; Board on Global Health; Institute of Medicine; National Academies of Sciences, Engineering, and Medicine. A Framework for Educating Health Professionals to Address the Social Determinants of Health. Washington, DC: National Academies Press, 2016. CrossRef

9. Jones CP. Levels of racism: a theoretic framework and a gardener's tale. Am J Public Health. 2000:90: 1212-5. CrossRef
10. Geiger HJ. The political future of social medicine: reflections on physicians as activists. Acad Med. 2017;92:282-4. CrossRef

11. Abu-Odeh D, Martos AJ, Sheffer CE. Teaching population health to medical students through the community health assessment. Educ Prim Care. 2017;28:237-42. CrossRef

12. Association of American Medical Colleges. Tool for Assessing Cultural Competence Training (TACCT). https:// www.aamc.org/initiatives/tacct/. Accessed August 26, 2017.

13. Association of American Medical Colleges. Health equity research and policy, https://www.aamc.org/initiatives/ research/healthequity/. Accessed July 12, 2017.

14. Beyond Flexner Alliance home page. http://beyondflexner. org/. Accessed July 12, 2017.

15. Social Medicine Consortium home page. http://www. socialmedicineconsortium.org/. Accessed August 26, 2017.

16. World Health Organization. The Commission on Social Determinants of Health - what, why and how? http://www. who.int/social_determinants/thecommission/finalreport/ about_csdh/en/. Accessed August 26, 2017.

17. University of Wisconsin School of Medicine and Public Health. ForWard curriculum. http://www.med.wisc.edu/ education/md-program/main/276. Accessed August 26, 2017.

18. University of Wisconsin School of Medicine and Public Health. Wisconsin Academy for Rural Medicine. http://www. med.wisc.edu/education/md/wisconsin-academy-for-ruralmedicine-warm/main/187. Accessed August 26, 2017.

19. University of Wisconsin School of Medicine and Public Health. Training in Urban Medicine and Public Health. http:// www.med.wisc.edu/education/md/triumph/training-in-urbanmedicine-and-public-health/681. Accessed August 26, 2017.

20. Haq C, Lemke M, Buelow M, Stearns M, Ripp C, McBride P. Training in Urban Medicine and Public Health: preparing physicians to address urban health care needs. WMJ. 2016;115:322-5.

21. Solberg LI, Asche SE, Butler J, et al. Patient-centered outcomes measurement: Does it require information from patients? J Patient Cent Res Rev. 2017;4:221-9.

22. Hammarlund R, Hamer D, Crapanzano K, et al. Health care disparities knowledge, attitudes, and behaviors in resident physicians. J Patient Cent Res Rev. 2017;4:230-6.

23. Dillon EC, Tuzzio L, Madrid S, Olden H, Greenlee RT. Measuring the impact of patient-engaged research: how a methods workshop identified critical outcomes of research engagement. J Patient Cent Res Rev. 2017;4:237-46.

24. LeCounte ES, Swain GR. Life expectancy at birth in Milwaukee County: a zip code-level analysis. J Patient Cent Res Rev. 2017;4:213-20.

25. Cardarelli R, Weatherford S, Schilling J, et al. Improving chronic pain management processes in primary care using practice facilitation and quality improvement: the Central Appalachia Inter-Professional Pain Education Collaborative. J Patient Cent Res Rev. 2017;4:247-55.

(C) 2017 Aurora Health Care, Inc. 